SH

211

G216

1883

FISH

\title{
DIVISION OF FISTES
}

ISSUED BY AUT HOS TEATIONAL MUSTID

\section{PAPERS OF THE CONFERENCES}

- Held in connection with

The GREAT dN TIERT FISHERIES FXHIBITION

THE

BASIS FOR LEGISLATION ox

FISHERY QUESTIONS

\author{
av
}

LIEUT.-COLONEL FRANCISCO GARCIA SOLA SECRETARY OF THE SPANISH COMMISSION AT THE INTERNATIONAL FISHERIES EXHIBITION

\section{LONDON}

7. WILLIAM CLOWES AND SONS, LIMITED INTERNATIONAL FISHERIES EXHIBITION AND 13 CHARING CROSS, S.W. 


\section{PAPERS OF THE CONFERENCES}

\section{Held in connection with the GREAT INTERNATIONAL FISHERIES EXHIBITION.}

NOW READY.

Demy 8vo, in Illustrated Wrapper. Price Sixpence each.

INAUGURAI MEETING: ADDRESS. By Professor HUXLEY, P.R.S. H.R.H. the Prince of WArES (P.esident of the Commission) in the Chair.

NOTES ON THE SEA FISHERIES AND FISHING POPULATION OF THE UNITED KINGDOM. BY H.R.H THE DUKR OF EDINBURGH, K.G. Is.

THE FISHERY INDUSTRIES OF THE UNITED STATES. By Professor BROWN GOODE, M.A.

OYSTER CULTURE AND OYSTER FISHERIES IN THE NETHERLANDS. By Professor Hubrecht.

PRINCIPIES OF FISHERY LEGISLATION. By Right Hon. G. SHAw. LEFEVRE, M.P.

ON THE CULTURE OF SALMONIDAE AND THE ACCLIMATiSATION OF Fish. By Sir James Ramsay Gibson Maitland, Bart.

FISH DISEASES. By Professor Huxley, P.R.S.

THE ECONOMIC CONDITION OF FISHERMEN. By Professor LEONE LEVI.

THE FISHERIES OF CANADA. BY L. Z. JONCAS.

PRESERVATION OF FISH LIFE IN RIVERS BY THE FXCLUSION OF TUWN SEWAGE. By the Hon. W. F. B. MASSEY MaINwarinf.

MOLLUSCS, MUSSELS, WHELKS, \&c., USED FOR FOOD OR BAIT. By Charles Harding.

COARSE FISH CULTURE. By R. B. MARSTON.

ON THE FOOD OF FISHES. By Dr. F. DAY.

THE HERRING FISHERIES OF SCOTLAND. By R. W. DUFF, M.P.

LINE FISHING. BY C. M. MUNDAHL.

FISH TRANSPORT AND FISH MARKWTS. " By His Excellency SPENCER WALPOLE.

FOREST PROTFCTION AND TREE CULTURE ON WATER FRONTAGES. By D. Howitz, Esq.

SEAL FISHERIES. By Captain TEMPLE.

FISH AS FOOD. By Sir HENRY THOMPSON.

STORM WARNINGS. By R. H. SCOTT.

ON THE DESTRUCTION OF FISH AND OTHER AQUATIC ANIMALS BY INTERNAL PARASITES. By Professor CoBbold, F.R.S., F.L.S.

SCIENTIFIC RESULTS OF THE EXHIBITION. By Professor E. RAY LANKESTER.

A INATIONAL FISHERY SOCIETY FOR GREAT BRITAIN. By C. E. FRYRR.

CRUSTACEANS. By T. CORNISH.

TRAWLING. BY ALFREU ANSELt.

THE BASIS FOR IFGISLATION ON FISHERY QUESTIONS. By

Lieut.-Col. F. G. Sozí.

IN THE PRESS.

SALMON AND SALMON FISHERIES By DAVID MILNE HOME, F.R.S.E. PILCHARD AND MACKEREL FISHERIES. By T. CORNISH.

FRESH-WATER FISHING (other than Salmon). By J.P. WHEELDON.

ARTIFICIAT CULTURE OF LOBSTERS. By W. SAVILLE KENT.

ON FACILITIES FOR THE IMPROVFD CAPTURE AND FCO-

NOMIC TRANSMISSION OF SEA FISHES, AND HOW THESE MATTERS AFFECT IRISH FISHERIES. By R. F. WALSH, of Kinsale.

THE FISHERIES OF IRELAND. By J. C. BLOOMFIELD.

THE FISHERIES OF OTHER COUNTRIES. By Commissioners for Sweden, Norway, Spain, \&c., who took part in the Conference.

LONDON : WILLIAM CLOWES \& SONS, LIMITED, INTERNATIONAL FISHERIES EXHIBITION, \& 13, CHARING CROSS. 
G216 International Fisheries Exhibition

1.883

LONDON, I 883

FISH

\section{THE}

BASIS FOR LEGISLATION

ON

FISHERY QUESTIONS

BY

LIEUT.-COLONEL FRANCISCO GARCIA SOLÁ

SECRETARY OF THE SPANISH COMMISSION AT THE

INTERNATIONAL FISHERIES EXHIBITION

LONDON

WILLIAM CLOWES AND SONS, Limited

INTERNATIONAL FISHERIES EXHIBITION

AND 13 CHARING CROSS, S.W.

I 883 
LO N DON :

PRINTED BY WILLIAM CLONES AND SONS, LIMITED, STAMFORD STREET AID CARING CROSS. 


\section{International Fisheries Exhibition, L O N D N, I 883 .}

Conference on Thursday, July i9, i883.

His Excellency the Marquis DE CASA-Latglesia, the Spanish Minister, in the Chair.

\section{THE BASIS FOR LEGISLATION ON FISHERY QUESTIONS.}

WHEN we speak of the depletion, or complete exhaustion of fisheries, it must be understood that these terms are not used in an absolute sense, but only so far as they affect the supply for the use of mankind, or, in other words, the output of the industry. The quantity of fish may be diminished in two ways, in the one case, when the catch exceeds the reproduction, and in the other, when the fish are frightened away from the haunts of the fishermen. I quite agree with the views so often expressed as to the difficulties which have hitherto stood in the way of a proper study of the life and habits of the inhabitants of the sea, which is the only thing that would conduce to an early solution of the problem ; but the experience gained from ascertained facts concerning fisheries, throws enough light to induce a conclusion, in any rational mind, in one or the other direction.

With regard to sedentary species, I do not think there is the least doubt that these can be exhausted by being overfished, or by improper methods of fishing, since it is 
clear that if a natural oyster-bed, for example, be dredged constantly and no time left for its reproduction, it will amount to the same thing as if one repeatedly dredged stones or other inert material-that is the bottom would at last be perfectly clear of them.

Such an obvious argument as this needs no confirmation, but if any such confirmation were needed, we might cite what has occurred on the north-west coasts of Spain, where, until the beginning of the present century, so great was the quantity of oysters in the beds that they were sold at four cuartos, or a little more than one penny per hundred, while the present price averages I 2 pesetas or $9 s .7 d$. for the same quantity. Even if we take into account the small consumption at that time, owing to defective means of communication, this circumstance is insufficient to explain the enormous difference just mentioned, which points clearly to the complete exhaustion of the beds.

With regard to species which lead a more or less migratory existence, there cannot be the least doubt that if man had complete control over the area occupied by each, the same principle of more fish being caught than could be reproduced would lead to exhaustion likewise ; what has to be determined is, how far man has such control in a given locality. The old fishermen of the Mediterranean relate that they remember having seen in their boyhood, species which they do not see now, but we need not attach any great importance to such a statement, until we have the means of ascertaining whether the fish have gone out to deep waters, but if there should be no communication between two seas, and they were really exhausted under certain conditions, this fact would of itself prove the theory of exhaustion just propounded. The case is, however, different with the ocean, the immensity of which makes extermination 
impossible except in the case of fish whose nature leads them to resort to the shore for spawning purposes or for food.

This immensity and the impervious conditions of the element in which fish live, throw such obscurity over their mysterious life that it is not possible to pronounce an opinion upon this question, except so far as we are in a position to do so from observations made from the coast and its surrounding waters, and even then the comparisons must extend over long periods of time. It is well known that both on land and sea many species of animals have entirely disappeared, and their fossil remains alone come down to confirm historical references. But without going back to such early times, we may refer to the great diminution in the number of whales within the present century, a diminution probably more owing to the voracity of other aquatic animals than to overfishing by man.

We can also cite the diminution of the smaller species in proof of our assertion, the tunny, for example, as referred to by ancient historians. Strabo and Pliny both call attention to the enormous quantities of this fish caught by the Phœnicians, and the arm of the sea near Constantinople owes its designation of the Golden Horn to the immense wealth which the Byzantines drew up from it in the shape of tunnies, and lastly, Caio Plinio mentions the fact of the fleet of Charles the Great encountering a shoal of tunnies which altogether impeded his progress. In much later times the reports of the erudite Father Sarmiento give particulars as to this fishery, from which we can judge of its decline; the reports showing much greater quantities than those now obtained.

The tunny is a migratory fish living in the deep sea, and returning every year to the eastern parts of the Mediterra- 
nean, at the same season, to spawn, following the line of the European continent when it arrives, and on its return after spawning, taking the coast of Africa and passing on through the Straits of Gibraltar to the Atlantic.

Now it will be easy to explain the diminution of this fish since historic times, by the fact that of the great quantities which enter the Mediterranean to spawn some are caught by the fishermen after spawning, but the great majority before fulfilling this function. How then can we conclude that the cause of this diminution is not owing to the action of man ?

It is quite true that many centuries may elapse before the complete extinction of a migratory species from the vast expanse of the main; perhaps before this exhaustion takes place some of those abnormal conditions may occur in the history of our planet which will disturb the essential conditions of the history of those species, but even in this remote contingency we must not lose sight of the fact that the biological regions are not unlimited, and that every species seeks out its abode where nature and its kindred elements have produced the required conditions, some species being only able to live in low temperature, others in high ones, some again cannot live in estuaries, and those species which are limited by temperature are again subdivided into others separated by the pressure of the waters, some being obliged to live at a great depth compared with others, and among other limitations there is the question of food and shelter, the appropriate motion of the currents ; and lastly, that the depletion be not carried to such an extent as to prejudice food-supply, and thus be the first step towards an end of the industry.

It is now time to enter on the second head of the theory propounded. We have said that the depletion of the 
fisheries or their complete exhaustion is not referred to in its absolute sense, but only in the sense of their use for mankind, and from this point of view let us demonstrate the most practical point, viz., that in which fish are compelled to abandon places which are within the reach of fishermen.

It is not the opinion of Spanish fishermen exclusively that the sea fisheries are inexhaustible, but it is an idea that gains general credence; they know the fabulous reproductive power of fishes, they contemplate the huge expanse the fish live in, which they suppose to be full of the species they try to catch ; they compare these spaces and their enormous population with those actually taken, and the distance run, then, without troubling their heads further on the matter, jump to the firm conviction that fisheries are inexhaustible. They let down their nets into the sea eager to gather in the fruits of their precarious calling, only to draw them up empty, try a second and third time with the same result, and then return home to think on the bad issue of their day's toil ; and when this is repeated day after day they attribute it all to the variation of currents, to atmospheric influences, to the noise of artillery on vessels and on shore, to the transit of steam ships through the fishing grounds, to epidemics among the fish, to caprices of fortune, to witchcraft, and, in fine, to anything and everything, rather than the destruction caused by an overworking of the fisheries.

Sometimes a more thoughtful individual attributes this to the method of working the fishing tackle, he notices that the drag nets in sweeping the bottom bring to the surface rooted up vegetation which serves as pasture for one species, as shelter for another, and as a nursery for the young of others, and also observes that among the entangled herbage are myriads of germs and young fry macerated by the 
dragging; he counts up the grand total of individuals destroyed by such a proceeding, and then reflects on the enormous quantity represented by the wholesale destruction of so oft repeated a system among all maritime nations, and then arrives at his conclusion as to the part man plays in the depletion of fisheries, and if he knows too that the shallow bottoms in proximity to the shore are the necessary spawning places of many species, he can entertain no doubt that the present methods of fishing are disastrous.

Not being able to entertain any principle not sanctioned by practice, let us next examine what in their essentials are these fishing utensils used in different numbers and slight variations of detail in nearly every country. They consist of two bands of net, with a bag or sack of the same material but of much closer texture, the borders or lower ropes of the sack being provided with leads throughout their length, to insure the sinking of the net, and on the upper ropes are attached cork or other material of a lighter specific gravity than water to cause them to float, by this means keeping the nets vertical and the mouth of the sack open. The net thus reaches the bottom of the sea, and at the extremity of both bands there are attached two cords, generally of great length, by which the apparatus is dragged on shore by one or two boats, according to the class to which it belongs.

Hence it will be seen that these nets can only be used on flat bottoms without stones or other obstacles to catch them. The net in its passage roots up the vegetation which grows in such places and hauls them to the surface or on shore; these are found entangled in the net in great quantities, and with them during the spawning season of those species which spawn along the shore one encounters among the seaweed multitudes of eggs more or less 
developing, and young fish crushed completely by the movement of the apparatus. That these facts reveal an enormous quantity of fish destroyed in repeated castings there should arise no sort of doubt, and the same thing has been seen by me on various occasions in the bou or chalut, which is worked by boats in the Mediterranean and in the southern ocean of Spain, as well as in the jábegas and bolickes, which drag from land throughout the Spanish continent whenever they find suitable localities. I have seen more than this. I have seen in the Gulf of Valencia drawn up in the sack of one of these nets so great a quantity of red mullet that they were all caked together, such was the maceration to which this delicate fish had been subjected, although the injury was the cause of a much less price being obtained for fish captured in this manner.

Of the disastrous results of this fishery we have unquestionable examples in Spain. A law fixed an imaginary zone near to land within which this kind of fishing was prohibited, and when at the end of some years the fishery of non-prohibited places was exhausted, application was made to fish within the zone, the Government prudently refused to permit it. A close time having been also appointed the fishermen asked that it might be deferred. At some places, Malaga among them, the fishermen who had used these nets for years growing tired of the damage they caused to their catch, bought them all up and burned them, at the same time petitioning the government for their extermination from the province. Now what do these facts prove? They prove without a shadow of doubt two things. The first, that fish obtained by trawling are of inferior value to those caught with hooks or floating nets, on account of the crushing which renders them liable to early putrefaction. Secondly, that in those places where trawling is allowed, the 
fish are all completely extinct. Against these facts no argument is possible.

Exactly the same thing takes place with trawling gear plying nearer the shore. Thus the jabega had spots appointed to it along the coast, and after working for some years completely denuded them of fish. The boliche had to change its position for exactly the same reasons, likewise the boliche de rada which operates in small areas where fish are brought for sale and to be salted. Even on the coasts of those countries which have ground suitable for this gear, the fish are so pursued that they do not remain permanently, having no means to satisfy their necessities.

It is not only this gear which operates injuriously on the produce of the waters on the coast, but the use of poisonous materials and explosive substances and stakes in the embouchure of rivers, with many other things by which man mars the spontaneous production of the finny tribes. Two evils are attached to the use of explosives, the fish caught by it die without distinction of size (it telling with especial force on the young), and the noise frightens those that escape alive. In poisoning the waters the fish are of course deprived of the means of living in them, at the same time that the dead ones are rendered unfit for food, and repugnant to the public taste. With regard to the damage done by stakes at the entrance to rivers it must be remembered how many littoral species ascend to spawn in the limpid bottoms whose fine sands aid them in depositing their eggs, and afford facilities for impregnation in these tranquil places, which would not occur in frequented localities. It speaks nothing with respect to these impedinıents to transit, that certain species live both in fresh and salt water, since the wise English law on salmon fisheries expressly prohibits them. The result of not having 
a similar law in Spain is that, while at the end of last century and the beginning of this, this fish was so abundant in the rivers of the north and north-west of Spain, that servants bargained with their masters'that they should not eat salmon more than two days a week; the price is now so high in the capital as to place it beyond the reach of all but the highest grades of society, and even what is there consumed comes in a great part from abroad. This state of things points to the necessity of legislation, and in consequence, the question of a change in the law is at present under consideration by competent authorities.

Having shown and explained the injury occasioned in Spain by abuses in the fisheries, and also the necessity for placing rational restrictive measures on the working, it will doubtless be asked whether, owing to the extent of the prejudices existing on the subject, the very fishermen for whose benefit they were put forward would not ignore them. Their objection has very little practical importance and can easily be met. In the first place fishermen desire only to have plenty of fishing and to have it at little cost. In the second-when they know the causes of the evilit is necessary for them to employ all their energies and make some sacrifice to respect the means of reproduction, because if only a few abstained from joining the concourse the whole thing would be a failure. If the sea could be subdivided like the fields, so that each section would respect reproduction and would not gather in the harvest till it was ripe, there would be no need for restrictive measures, but since the exploration of the deep is common property there can be no remedy but such as is obtained by the Government of each country. The necessity for this not only interests fishermen, but is a question of the food supply of nations. 


\section{LEGISLATION.}

IT has been shown on all sides that if the abuses practised in fisheries be not substantially ameliorated the fish will either be frightened away, or abandon the stations, which amounts to the same thing, since it matters little to a country that the normal reproduction is kept up, if they are not available for food.

Hence the necessity of remedial measures for the existing evils. But what shall these measures be? That is the question we must answer, a question too complex to be defined, since it depends on a multitude of contradictory elements. The natural condition of the waters, the diversity of creatures sought out from it, the differences in the life and habits of those creatures, and the obstacle which the element they live in presents tu a study of those habits, have allowed very few persons to study ichthyology: whilst the inhabitants of a country, their social condition and fundamental laws, and lastly the free concurrence of individuals in a common ground of action, are among the many elements which complicate the solution of the problem.

The principle for fishery legislation on a sound basis is a very simple one, and merely consists in the establishment of equilibrium between the spontaneous production of the waters and that which is drawn out of them. But the carrying out of this principle and making the regulations to meet it doubtless present a multitude of insuperable difficulties.

An absolutely restrictive system and one which would cut at the root of those inveterate abuses sanctioned by constant practice and of old date, however well considered and reasonable it may be, will inevitably meet with an opposition 
difficult if not impossible to overcome. In the first place, under the shade of those abuses established, recognised, or tolerated by former laws, there will have grown up a crowd of well-to-do interests which it is not possible to disregard, and hence the necessity for a fundamental principle of the law dealing with such cases, if the State does not take measures for satisfying them pecuniarily, of which case we have in Spain so eloquent an example.

It results from what has been said that the Government should prevent the use of trawling gear, called bou, since ample information and an attentive study show the evident necessity for putting an end to this system of fishing. It has been proposed to issue regulations imposing on its excrcise specified limits of time and distance, and forbidding the employment of new gear, but this suggestion is of no avail in practice, as the possessors of such gear naturally desire to keep them as long as possible and never proceed to break them up. Thus the essential point of the law is evaded, which would not be the case if the government bought up the apparatus and awarded compensation, at the same time absolutely forbidding the employment of such apparatus in fisheries.

In imposing a system of absolute restrictions, it must not be forgotten that these will be sure to provoke an unpopularity which no government can afford to disregard.

If, on the other hand, we pass to the opposite point, viz.,. altogether frce working, it is a Utopian idea that by this means equilibrium will be maintained between production and extraction without any government intervention, as was recently done in the United States in the way Professor Brown Goode so clearly explained to us.

We do not know, however, if this modern procedure will give in the course of time the cxpected favourable results, 
and years must clapse for its thorough trial, but we believe it will-we belicve so because we have great faith in the progress of that grand nation; but on the other hand we do not believe it will cure all ills, for it is a principle contrary to reason that fishermen should destroy and government reconstitute. But to clear this question from the density of the waters, we must fancy ourselves on land and suppose that in working the mountains of a nation the same means were adopted, viz,, unrestricted felling of trees and wood, the government being charged with replenishing them at the cost of the State. The system would render the mountains still more costly and unproductive, for if the nursery grounds contained enough trees for restocking them, they would not replace those cut down in their natural size.

This is the weak side of the system, as establishments conveniently distributed along the coast are not sufficient to maintain the fundamental equilibrium of production, if when young fish are drawn out of the waters they are not returned to acquire maturity, and for this the action of the law, in a restrictive sense, is necessary at the present time.

Besides, to ensure the completeness of the system, it is necessary that these establishments should be of sufficient number and possess suitable conditions for the reproduction of the various edible specics, as otherwise what the system would gain on the one side, it would lose on the other, and this presupposes a heavy outlay on the construction and maintenance of the hatcheries.

We do not wish to censure a system, adopted with so much success in the United States, which assumes that the best way to ensure perfect working is to leave it in the hands of the workers to spontancously guard their own interests without the intervention of the State, because by this 
means there springs up a knowledge of reproduction, they see for themselves the advantages obtained by preservation, the rude operators learn something of the life and habits of the species kept at the stations, in a word, men who have hitherto thought only about fishing, think about the stocking of fishing grounds.

One word with respect to the fry proceeding from these cstablishments. This is the vulnerable point of the system. The United States consigns them to the care and watchfulness of protecting societies, but the representatives of other nations, who do not act in this spirit of association, and are not in a condition to bear the increasing expenses of a complete plan of fish hatching establishments, will agree with me, that however excellent may be the system under discussion, it is not fit for general adoption, having no other resource but that of looking to the State to keep up the production by means of a provisional law, which, while giving every possible limit to the industry, contributes in a marked degree to prevent the depletion of the fisheries.

These limitations cannot be determined in a general sense, because in them there enter conditions which cannot be disregarded, conditions which spring, some from nature itself, others from the laws, usages, and customs of each particular nation. It will hence be seen how much in common are the interests of fishing in all countries, all having the same fundamental principle, and it will then be possible to adopt measures having the same affinity and end.

In the first place it is necessary to take into account the fact that the same principles cannot be established in all waters. Thus Spain bounded by two distinct seas finds it necessary to depart from the general unity which applies to cvery national law, the industry being carried on under 
different conditions. The coast of the Mediterranean which undoubtcdly, as has been shown, produces more than the Atlantic coast, has great depletion in fish notwithstanding the most favourable conditions for reproduction-and there can be no doubt that this is due to abuses or the bad system of fishing practised by all countries which border on the sea. In the first place the means of extraction are greater, as the condition of these waters and that of the bottoms is more conducive to the establishment of impediments to fish passage than to trawling, also that the Mediterranean is more suitable to certain species. Notwithstanding this, its temperature, the class of vegetation which flourishes on its bottom, and the material organism which it constantly receives from the rivers and rainy deposits, are other elements which favour a large production.

\section{PROPOSALS.}

I will conclude by making somé proposals to my colleagues the Commissioners of all the countries represented at this Exhibition.

The importance of fisheries as the source of wealth is now recognised by all civilised countries, nor is it forgotten that it forms one of the principal elements in the public food supply, as well as that their cxtension facilitates the means of communication among nations, and that this increases the industrial output; and lastly, that the calling of a fisherman is the nursery which produces that race, hardy, enduring, and brave, which man our ships, establish means of communication among continents, and maintain the independence of nations.

All are interested individually and collectively in this calling and in the rational protection of the industry, because 
nature has provided no frontiers for the watery inhabitants, and the immensity in which they live manifests eloquently the interest which ought to be taken by nations to maintain this richness of production.

It is necessary for this that men of all countries who devote themselves to the study and administration of the different branches constituting this industry, should communicate one with the other to compare observations, resolve their doubts, and give statistics; it is necessary, too, that they should follow the example of England and seize an occasion to facilitate the interchange of products of all countries concerned; and it is necessary, lastly, that congresses should be held at which may be elucidated technically all points of controversy, thus founding a basis for international treaties.

Spain has established fishery boards in all her maritime provinces, and the Administration of these in the Ministry of Marine will gladly enter into relations with all the Commissions now established, or to be established, for the mutual interchange of matters tending to facilitate a knowledge of this important industry.

This community of interests is more apparent among nations of the same continent, since in the exercise of fishing, interests are affected in a reciprocal way, in the case of emigrants or passengers along the shore, and even the sedentary coast inhabitants. Many practical examples could be cited of common injuries, but I will limit myself to one.

The French fishermen used to fish in free waters off Arcachon with a trawling-net which they call "chalut," and the places they dragged they thought to be a bank or natural bed of sea bream and other shore species. Seeing that in Spain there was a diminution of these species, the 
Spanish fishermen went to work also (as the place was equally free to both nations, ) destroying the means of production of those species, which would naturally tend to seek another place farther off, with an appreciable loss to both Spaniards and Frenchmen.

It is necessary, therefore, that we should endeavour, considering the universal interests involved, to recommend in our respective countries the necessity of coming to an agreement by means of international treaties, so that the abuse of one nation may not prejudice the others.

It is evident that it is an error to consider the boundaries of national waters as the measure of international jurisdiction, because fish cannot be made to respect these limitations, which only apply to other matters, and more space is required in order that the bordering nations may watch over their preservation, not abandoning it as they do now by reason of this small territorial limit.

I will conclude with a point of great importance. We are all deeply impressed with the sufferings to which the fisherman is subject in his precarious occupation, ending in many cases in an untimely death; and as we have already said the waters have no frontiers, neither have human sentiments. It follows then that all coasting nations may afford protection from some of the sailor's perils by means of benevolent socicties, giving relief in cases of shipwreck and in any other disasters contracted in the calling.

All nations should combine for the mutual aid and propagation of societies of this nature, by means of which the man, well-to-do and exempt from perils, fulfils one of his most sacred duties-the relief of the poor hardly-worked fisherman.

At the conclusion of the Paper, the ChaIrman said it had been considered wiser to defer the discussion upon it, 
as a great many of the foreign delegates were absent, having gone to Scotland to inspect Sir James Maitland's fish culture arrangements at Stirling. He would therefore only propose a vote of thanks to Lieut.-Colonel Solá for his Paper.

The vote of thanks having been passed,

Mr. BIRkBECK, M.P., moved a similar vote to his Excellency for presiding, which was carried unanimously, and the Conference then adjourned. 
LONDON :

PRINTED BY WILLIAM CLOIVES AND SONS, LIMITED, STAMFORD STREET AND CHARING CROSS.

Wiargiormed by

Presorvation

Services

min $* 6073.09$ 


\section{OFFICIAL PUBLICATIONS}

OF THE

\section{INTERNATIONAL FISHERIES EXHIBITION,}

PUBLISHED BY

WM. CLOWES \& SONS, Limited, 13, Charing Cross, S.W.

(And Sold at their Stalls near each Entrance to the Exhibition.)

\section{OFFICIAL GUIDE BOOKS, \&C.}

LARGE PLAN and TOUR of the BUILDINGS, 1d.; post-free $1 \frac{1}{2} \mathrm{~d}$.

GUIDE to the EXHIBITION, 3d.; post-free $4 d$. PROGRAMME of MUSIC, \&c., 2d.; post-free 3d. OFFICIAL CATALOGUE, Second Edition, 1s.; postfree 1s. $4 d$.

CHEAP RECIPES for FISH COOKERY. Prepared by Mrs. CHARLES CLARKE. 3d.; post-free $4 \mathrm{~d}$.

\section{THE FISHERIES PORTFOLIO:}

CONTAINING

Ten Original Etchingss of Scenes on the British Coast. TITLE.

ARTIST.

I.-Bait Gatherers . - . . R. W. MAcbeth, A.R.A.

2.-Running Ashore . . . . COLIN Hunter.

3.-A Fisher Girl : . . . . J. D. Watson.

4.-Fishing Boats off Hastings - David LAw.

5.-Going for Bait . . . . . OTTO LEYDE, R.S.A

6.-Boat Building on the Yare . . C. J. WatTs.

7.--Preparing for Sea-Hastings - C. P. Slocomвe.

8.-Ramsgate Harbour . . . . . J. P. Heseltine.

9.-Fisherman's Haven . . . . J. MAcWhirter, A.R.A.

10.-Stranded-Rye. . . . . . WILfRID W. BALL.

Price 15 s. the complete set.

LONDON : WILLIAM CLOWES \& SONS, LiMITED,

TIONAL FISHERIES EXHIBITION, \& 13 CHIARING CROSS. 


\section{OFFICIAL PUBLICATIONS. \\ $\longrightarrow 0 \%$ room}

The following Handbooks upon subjects cognate to the International Fish or in active prepar

Demy 8vo, in Illus

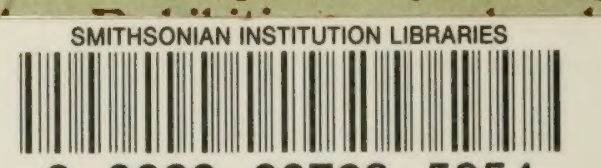
published, 39088007235054

2s. each.

THE FISHERY LAWS. DY FREDERICK rULLUCK, Barrister-atLaw, M.A. (Oxon.); Hon. LL.D. Edin. ; Corpus Christi Professor of Jurisprudence in the University of Oxford.

ZOOLOGY AND FOOD FISHeS. By George B. Howes, Demonstrator of Biology, Normal School of Science, and Royal School of Mines, South Kensington.

BRITISH MARINE AND FRESHWATER FISHES. (Illustrated.) By W. SAville KeNT, F.L.S., F.Z.S., Author of Official Guidebooks to the Brighton, Manchester, and Westminster Aquaria.

APPARATUS FOR FISHING. By E. W. H. HoLdSWORTH, F.L.S., F.Z.S., Special Commissioner for Juries, International Fisheries Exhibition; Author of "Deep Sea Fisheries and Fishing Boats," "British Industries-Sea Fisheries," \&c.

THE BRITISH FISH TRADE. By His Excellency SPENCER

WALPOLE, Lieut.-Governor of the Isle of Man.

THE UNAPPRECIATED FISHER FOLK. By JAMES G. BERTRAM, Author of "The Harvest of the Sea."

THE SALMON FISHERIES. (Illustrated.) By C. E. FrYer. Assistant Inspector of Salmon Fisheries, Home Office.

SEA MONSTERS UNIMASKED. (Illustrated.) By HENRY LEE, F.L.S.

THE ANGLING CLUBS AND PRESERVATION SOCIETIES OF LONDON AND THE PROVINCES. By J. P. WHEELDON, late Angling Editor of "Bell's Life."

INDIAN FISH AND FISHING. (Illustrated.) By FRANCIS DAY, F.L.S., Commissioner for India to International Fisheries Exhibition.

IN THE PRESS.

THE HISTORY OF FISHING FROM THE EARLIEST TIMES. By W. M. ADAMS, M.A. (Oxon.), late Fellow of New College.

FISH CULTURE. (Illustrated.) By Francis DaY, F.L.S., Commissioner for India to International Fisheries Exhibition.

FISH AS DIET. By W. Stephen Mitcheld, M.A. (Cantab.)

ANGLING IN GREAT BRITAIN. By WilliaM SENIOR ("Red Spinner").

EDIBLE CRUSTACEA. By W. SAville Kent, F.L.S., F.Z.S., Author of Official Guidebooks to the Brighton, Manchester, and Westminster Aquaria.

THE LITERATURE OF SEA AND RIVER FISHING. By JOHN J. MANLEY, M.A. (Oxon.)

SEA FABLES DISCLOSED. By HENRY LEE, F.L.S.

FOLK LORE OF FISHES: their Place in Fable, Fairy Tale, Myth, and Poetry. By Phil Robinson.

THE OUTCOIME OF THE EXHIBITION. By A. J. R. TRENDELL, of the Inner Temple, Barrister-at-Law, Literary Superintendent for the Fisheries Exhibition.

LONDON :

WILLIAM CLOWES AND SONS, LIMITF, INTERNATIONAL FISHERIES EXHIBITION, \& $3_{3}$, CHARI 